\title{
Presence and distribution of current-use pesticides in surface marine sediments from a Mediterranean coastal lagoon (SE Spain)
}

\author{
R. Moreno-González ${ }^{1}$ • V. M. León ${ }^{1}$
}

Received: 17 September 2016/Accepted: 13 January 2017

(C) Springer-Verlag Berlin Heidelberg 2017

\begin{abstract}
The spatial and seasonal distributions of currentuse pesticides (CUPs), including triazines, organophosphorus pesticides, and tributylphosphate, were characterized in surface sediments from the Mar Menor lagoon during 2009 and 2010. The impact of two flash flood events on the input of CUPs and their distribution in the lagoon were also assessed. The total (dissolved + sorbed phase) input of CUPs in the two flash floods through the El Albujón watercourse into the lagoon was estimated at $38.9 \mathrm{~kg}$, of which $9.9 \mathrm{~kg}$ corresponded to organophosphorus pesticides and $5.5 \mathrm{~kg}$ to triazines. CUP distribution onto sediments was not homogeneous in the lagoon due to the different contaminant sources, sediment types, and the physicochemical and hydrodynamic conditions of the Mar Menor lagoon. Thirteen CUPs were detected in 2009 and 19 in 2010, including mainly herbicides, insecticides, and the additive tributylphosphate. Mean CUP concentrations in the lagoon were generally below $20 \mathrm{ng} \mathrm{g}^{-1}$, except for chlorpyrifos and tributylphosphate in 2010. The highest concentrations were detected in depositional areas of the lagoon, in the area of influence of the El Albujón watercourse and other wadis with groundwater contributions such as El Mirador (north) and Los Alcázares (east) and that of marine water from El Estacio
\end{abstract}

Responsible editor: Ester Heath

Electronic supplementary material The online version of this article (doi:10.1007/s11356-017-8456-0) contains supplementary material, which is available to authorized users.

R. Moreno-González rubiolfin@hotmail.com

V. M. León

victor.leon@mu.ieo.es

1 Instituto Español de Oceanografía, Centro Oceanográfico de Murcia, C / Varadero 130740 San Pedro del Pinatar, Murcia, Spain channel. In fact, the maximum concentration was detected close to El Albujón watercourse (chlorpyrifos, $102.8 \mathrm{ng} \mathrm{g}^{-1}$ dry weight). Four herbicides, two insecticides, two fungicides, and tributylphosphate showed a risk quotient higher than 1, with that for chlorpyrifos ranging from 96 to 35,200 after flash flood events.

Keywords Coastal sediments · Mar Menor lagoon · Triazines · Organophosphorus pesticides · Flash flood event . Risk quotients

\section{Introduction}

Coastal areas are a major asset for countries in which they are found, since they host numerous human activities (e.g., industrial, tourist, economic, transport) in addition to possessing great natural value. However, such activities can also lead to loss of water and sediment quality due to point and diffuse sources of organic pollutants associated with human activities affecting resident biota. A high spatiotemporal variability of the concentration of pollutants in water is observed in coastal areas (Carafa et al. 2007; Añasco et al. 2010; MorenoGonzález et al. 2013a; Campillo et al. 2013), which complicates the taking of representative samples, making other integrative matrices such as biota or sediments more useful; consequently, such matrices are used in many international monitoring programs (e.g., OSPAR, MED POL).

As a result of different physicochemical interactions (e.g., hydrophobic interactions, adsorption, chelation), and sediment properties, marine sediments tend to be a sink for many contaminants (e.g., trace metals, polycyclic aromatic hydrocarbons, organochlorinated contaminants) transported in dissolved phase or sorbed to particulate matter into the marine environment (Ridgway and Shimmield 2002). A fraction of 